ФОРМИРОВАНИЕ УСТОЙЧИВОЙ МОТИВАЦИИ

К ИЗУЧЕНИЮ ХИМИИ КАК СРЕДСТВА УГЛУБЛЕНИЯ ЗНАНИЙ

ФОРМУВАННЯ СТІЙКОЇ МОТИВАЦІЇ ДО ВИВЧЕННЯ ХІМІЇ

ЯК ЗАСОБУ ПОГЛИБЛЕННЯ ЗНАНЬ

\title{
FORMATION OF SUSTAINABLE MOTIVATION TO STUDY CHEMISTRY AS A METHOD OF DEEPENING KNOWLEDGE
}

Кризис химического образования углубляется. Наблюдается резкое снижение интереса учащихся к предмету. Решение министерства убрать химию из обязательных экзаменов ЗНО даже для медицинских и биологических специальностей ещё сильнее усугубляет проблему.

В работе показано, что интерес к химии следует формировать у самых младших школьников. Интерес - это лучший учитель, движущая сила для получения знаний и творчества в более позднем возрасте. Когда у ученика возникает интерес, тогда появляется энтузиазм, увлечённость, обучение доставляет радость. Мотивация занимает ведущее место в структуре личности, затрагивает все её основные аспекты: характер, эмоции, способности, деятельность, психические прочессы.

Особую роль в мотивировании при освоении дисциплины «Химия» играет лабораторный эксперимент. Эксперимент - важнейший путь осуществления связи теории с практикой при обучении химии. Велика значимость применения химического эксперимента при использовании учителем метода проблемного изложения материала. Эксперимент здесь может выступать как важнейший метод доказательства истинности или ложности выдвинутых гипотез. В статье рассматривается ряд сложностей объективного и субъективного характера, ограничивающих применение экспериментальных методов в курсе химии, основными из которых является недостаточное фринансирование, зарегулированность хранения токсичных, огнеопасных и иных веществ, отнесение многих общепринятых реактивов к прекурсорам.

Pешить часть проблем может так называемый домашний химический эксперимент, имеющей большое значение для развития интереса к химии. Как правило, этот вид эксперимента не требует ни дорогостоящего оборудования, ни труднодоступных реактивов; тем не менее опыты захватывающие и зрелищные, а их перечень в Интернете достаточно широк; даются ссылки на сайты.

Сложным является вопрос о перспективах превращения интереса к химии в реальную способность заниматься химией в будущем. Желательно заранее знать, способен ли ученик овладеть химическими компетенциями. В противном случае ему следует искать другую отрасль применения сил. Описывается решение проблемы диагностирования таких способностей по методу Г.В. Лисичкина. Диагностическая схема оказалась чрезвычайно полезной для ранней просрориентации школьников. В настоящее время она успешно используется для профрконсультаций.
Ключевые слова: интерес к предмету, мотивация, эксперимент, способности, химические компетенции.

Криза хімічної освіти поглиблюється. Спостерігається різке зниження інтересу учнів до предмета. Рішення міністерства прибрати хімію з обов'язкових іспитів ЗНО навіть для медичних $і$ біологічних спеціальностей ще більше погіршує проблему.

У роботі показано, що інтерес до хімії необхідно формувати у наймолодших школярів. Інтерес - че найкращий учитель, рушійна сила для отримання знань $і$ творчості в більш пізньому віці. Коли в учня виникає інтерес, тоді з'являється ентузіазм, захопленість, навчання приносить радість. Мотивація посідає провідне місце в струкmурі особистості, зачіпає всі їі основні аспекти: характер, емоції, здібності, діяльність, психічні процеси.

Особливу роль в мотивуванні під час освоєння дисципліни «Хімія» відіграє лабораторний експеримент. Експеримент - найважливіший шлях здійснення зв'язку теорії з практикою під час навчання хімії. Велике значення має застосування хімічного експерименту у разі використання вчителем методу проблемного викладення матеріалу. Експеримент тут може виступати як найважливіший метод доказу істинності чи хибності висунутих гіпотез.

у статті розглядається низка складнощів об'єктивного і суб'єктивного характеру, що обмежують застосування експериментальних методів у курсі хімії, основними з яких $\epsilon$ недостатнє фрінансування, зарегульованість зберігання токсичних, легкозаймистих та інших речовин, віднесення багатьох загальноприйнятих реактивів до прекурсорів.

Вирішити частину проблем може так званий домашній хімічний експеримент, що має великезначеннядлярозвиткуінтересудо хімії. Як правило, цей вид експерименту не вимагає ні дорогого устаткування, ні важкодоступних реактивів; проте досліди захоплюючі і видовищні, а їх перелік в Інтернеті досить широкий; даються посилання на сайти. Складним є питання про перспективи перетворення інтересу до хімії на реальну здатність займатися хімією в майбутньому. Бажано заздалегідь знати, чи здатний учень опанувати хімічні компетенції. В іншому разі йому слід шукати іншу галузь застосування сил. Описується вирішення проблеми діагностування таких здібностей за методом Г.В. Лисичкіна. Діагностична схема виявилася надзвичайно корисною для ранньої профорієнтації школярів. Нині вона успішно використовується для профконсультацій. Ключові слова: інтерес до предмета, мотивація, експеримент, здібності, хімічні компетенції. 
The crisis of chemical education is deepening. A sharp decrease in students' interest in the subject is observed. The decision of the ministry to remove chemistry from the obligatory examinations of ZNO even for medical and biological specialties aggravates the problem even more. The article claims that interest in chemistry should be formed in the youngest schoolchildren. Interest is the best teacher, the driving force for learning and creativity at a later age. When a student develops interest, then there is an enthusiasm, dedication, learning gives joy. Motivation takes a leading place in the structure of the personality, affects all its basic aspects: character, emotions, abilities, activity, mental processes.

A special role in motivation in the development of Chemistry is played by a laboratory experiment. An experiment is the most important way of connecting the theory with practice in teaching chemistry. A chemical experiment is of great importance when a teacher uses the method of problem presentation of material. An experiment here can act as the most important method of proving the truth or falsity of hypotheses that were put forward.

The article discusses a number of objective and subjective difficulties that restrict the use of experimental methods in chemistry courses, the main of which are insufficient funding, overregulation of the storage of toxic, flammable, and other substances, and the assignment of many generally accepted reagents to precursors.

Some of the problems can be solved by the so-called home chemical experiment, which is of great importance for the development of interest in chemistry. As a rule, this type of experiment requires neither expensive equipment nor hardto-reach reagents; nevertheless, the experiments are exciting and spectacular, and their list on the Internet is quite wide; links to sites are given.

The challenge is the prospect of turning of the interest in chemistry into a real ability to become a chemist in the future. It is desirable to know in advance whether the student is able to master chemical competencies. Otherwise, he should look for another branch of the use of his abilities. The solution of the problem of such abilities diagnostics by the method of G.V. Lisichkin is discussed. The diagnostic scheme was extremely useful for early career guidance of students. Currently, it has been successfully used for professional consultations.

Key words: interest in the subject, motivation, experiment, abilities, chemical competencies.
Постановка проблемы в общем виде. В последние годы наблюдается снижение интереса к химии у школьников общеобразовательных школ, снижается количество часов, отведённых для изучения химии, и возрастает объём изучаемого материала. Возникает противоречие между необходимостью химических знаний для современного человека и непониманием значимости изучаемого материала для практической жизни, противоречие между повышением теоретического уровня изучения предмета на начальном этапе и недостаточной сформированностью умения логически мыслить. Это является одной из причин резкого снижения интереса учащихся к предмету наряду с сильной теоретизацией учебного материала, недостаточным качеством учебников, ослаблением роли эксперимента и т.д.

Анализ последних исследований и публикаций. С точки зрения психологов и педагогов самый продуктивный для изучения фуундаментальных областей научного знания возраст - 10-13 лет, пятиклассникам химия более интересна, чем учащимся 8 класса.

Недаром, описывая свою положительную практику раннего привлечения детей, Д.М. Жилин [1] отмечает, что из всех образовательных наборов серии «Научные развлечения» набор «Юный химик» наиболее популярен и имеет несомненный коммерческий успех; причём основная масса потребителей - родители школьников 8-14 лет, то есть того возраста, когда химии в школе ещё нет и аттестация не может являться мотивацией для покупки достаточно дорогостоящего набора. Поэтому именно в этом возрасте необходимо помочь ссрормировать интересы к химии у младших школьников, ещё до начала официальных занятий по химии. Интерес - это лучший учитель, движущая сила для получения знаний и духовный источник изобретений и творчества в более позднем возрасте.

Химия является одной из самых значимых областей естествознания. Дисциплина «Химия» обязательна для изучения в университетах технического и естественнонаучного профриля, так как понимание законов химии и сущности фризикохимических явлений необходимо как для совершенства существующих, так и создания новых процессов, машин, материалов и приборов.

Успех работы специалиста в любой области во многом будет зависеть от качества химической подготовки. Однако в школах сокращается время, отводимое на изучение химии в старших классах до одного часа в неделю, соответственно, и студенты на младших курсах имеют невысокие результаты обучения ввиду недостаточных школьных знаний и отсутствия мотивации учения [2]. Как следствие, контингент первокурсников вуза обладает слабыми химическими знаниями и часто не способен воспринимать университетские курсы химии.

Но когда у ученика возникает интерес, тогда ситуация меняется, развивается особая химическая смекалка, появляется энтузиазм, увлечённость, обучение доставляет радость.

Повышению исходного уровня подготовки у студентов будет способствовать наличие у них устойчивой мотивации к учению. Мотивация занимает ведущее место в структуре личности и проникает во все её основные образования: направленность, характер, эмоции, способности, деятельность, психические процессы. Поэтому наличие у обучаемого устойчивой мотивации к приобретению знаний, умений и навыков позволит сформировать в нем устойчивый интерес к такому поиску, 
в частности, к самостоятельным изысканиям в избранной специальности, и создать твёрдое убеждение в том, что только целенаправленная, систематическая, в том числе и самостоятельная работа может сделать его подлинным специалистом и обеспечить его профессиональный рост по окончании вуза, повысить учебно-познавательную активность, наиболее полно реализовать интеллектуальный потенциал.

Важнейшим инструментом в создании мотивации к обучению химии является химический эксперимент. Ученик, проводящий опыты и наблюдающий химические превращения в различных условиях, убеждается, что сложными химическими процессами можно управлять, что в явлениях нет ничего таинственного, они подчиняются естественным законам, познание которых обеспечивает возможность широкого использования химических превращений в практической деятельности людей [3].

Выделение не решённых ранее частей общей проблемы. Несмотря на общее понимание необходимости мотивирования ученика относительно важности получения глубоких знаний в естественнонаучных областях, конкретных устоявшихся методик формирования устойчивой мотивации не существует. Отдельные преподаватели решают эту проблему самостоятельно в соответствии с их предпочтениями и компетентностью.

Целью статьи является дискуссионное осмысление литературных данных по фрормированию и закреплению мотивации к изучению химии, что может быть впоследствии использовано и в общемировоззренческом аспекте, и с целью профориентации. Развивается также тема возможной диагностики способностей учащихся к получению химических компетенций, без чего такая мотивация по сути теряет смысл.

Изложение основного материала. Изложенное выше свидетельствует об особой роли лабораторного эксперимента как средства мотивирования при освоении содержания дисциплины «Химия». Он является не только специфрическим методом, но и одновременно специфическим химико-образовательным средством. Химический эксперимент нужно проводить, поскольку он представляет собой самостоятельную ценность и личностно значим для школьников. Ни имитации, ни видеозаписи его не заменят. Естественно, эксперименты следует ставить так, чтобы их самостоятельная ценность и личностная значимость была максимальной.

Эксперимент - важнейший путь осуществления связи теории с практикой при обучении химии, путь превращения знаний в убеждения.

Химия - экспериментальная наука. Большинство химических знаний получено посредством искусственно осуществляемых процессов, а именно путём экспериментов. Обучение химии, как экспериментальной науке, должно быть наглядным и основанным на химическом эксперименте.

Особо следует подчеркнуть роль учебного химического эксперимента в формировании познавательного интереса у учеников как мотива познавательной деятельности, поскольку им определяются и направляются все психические процессы учения: восприятие, память, мышление, внимание и др. Очень важно, что химический эксперимент может быть использован как инструмент развития технического творчества (на уровне конструирования и сбора экспериментальных установок), но похоже, что это направление в методической литературе не рассматривается.

Велика значимость применения химического эксперимента при использовании учителем метода проблемного изложения материала. Деятельность педагога здесь заключается в постановке проблемы и раскрытии доказательного пути её решения через постановку эксперимента. При этом важно, чтобы ученики сами пришли к выводу о необходимости постановки соответствующих опытов, приняли бы участие в их разработке и проведении. И эксперимент здесь может выступать как важнейший метод доказательства истинности или ложности выдвинутых гипотез.

Современные дидактические модели типа case-study подчёркивают проблемный аспект эксперимента. Именно его проблемный характер даёт возможность не только устанавливать новые фракты, но и исправлять ошибки в знаниях студентов, уточнять и корректировать понимание отдельных вопросов курса химии.

Проблемные ситуации могут возникать в следующих случаях: при расхождении между имеющимися знаниями и наблюдаемыми новыми фактами и явлениями; при расхождении между имеющимися знаниями и новыми условиями их применения; при расхождении между теоретическими и практическими знаниями.

Новые проблемно-развивающие эксперименты и усовершенствованная методика их проведения должны помочь студентам в понимании и осознании многогранности изучаемых химических процессов, их природы, реальной сущности и зависимости от условий проведения.

Однако следует заметить, что проведение химического эксперимента, особенно школьного, наталкивается на ряд сложностей и объективного, и субъективного характера. Современный учебный химический эксперимент требует приобретения дорогостоящего оборудования, например, циорровых лабораторий, его ремонта, обновления, пополнения базы реактивов и т.д. Дополнительные проблемы связаны с требованиями по учёту прекурсоров наркотических и психотропных веществ. Исключение же химического экспе- 
римента из школьной практики позволяет сразу решить ряд проблем: существенно сэкономить выделенные школе средства, отменить «надбавки за вредность», сократить ставки лаборантов, исключить оборот и хранение прекурсоров, токсичных, огнеопасных и иных веществ. Учитель, сталкивающийся с перечисленными проблемами, зачастую не может переломить ситуацию. Постепенно утрачивается желание проводить химический эксперимент [4].

Ещё более запутана ситуация с юридическими основаниями материально-технического обеспечения школьного практикума по химии. По сути дела оно не регламентировано. Нормативы финансирования отсутствуют и, главное, непонятно, на чём они должны основываться.

Химический эксперимент в школах организуют учителя. Соответственно, чтобы вести химический эксперимент, учитель должен уметь и желать это делать. К сожалению, культура постановки и ведения химического эксперимента к настоящему времени в значительной мере деградировала.

В какой-то мере эту удручающую ситуацию, особенно на этапе раннего привлечения к химии, может разрешить домашний эксперимент. Как правило, этот вид эксперимента не требует ни дорогостоящего оборудования, ни труднодоступных реактивов; тем не менее опыты захватывающие и зрелищные, а их перечень в Интернете достаточно широк, например, только несколько русскоязычных [5] и англоязычных [6]

Однако ещё перед использованием средств к созданию у школьников устойчивой мотивации к изучению химии интересно было бы заранее узнать, способен ли ученик овладеть химическими компетенциями и в какой мере это ему доступно. В противном случае его дальнейшая профессиональная пригодность как специалиста химического профиля вызывает большие сомнения и следует искать другую отрасль применения сил.

Проблема подтверждения или отрицания существования способностей к химии и возможности их диагностирования поднимается во многих работах и, в частности, Г.В. Лисичкиным [7].

Он утверждает, что для достижения выдающихся результатов деятельности необходима совокупность у индивида задатков, положительных характерологических качеств личности, высокого интеллекта и креативности. Все эти компоненты важны, но ни один из них в отдельности не гарантирует успеха в профрессиональной деятельности. Задатки, не подкреплённые трудолюбием и настойчивостью, - это признак потенциально способных лентяев.

Как выявить у школьника наличие способностей к химии? На первый взгляд, ответ лежит на поверхности: надо предложить ему задания по химии различной степени сложности. Но так можно установить лишь уровень знаний, а не уровень способностей. Знания определяются не столько способностями, сколько условиями обучения, качеством преподавания. Вывод о том, что выявление способностей не есть выявление знаний, приводит к очень важному заключению - для диагностики наличия химических способностей изучение химии необязательно.

На основе обобщения полученных результатов Г.В. Лисичкиным и Л.А. Коробейниковой разработана комплексная схема тестирования химических способностей у школьников. Схема включает 29 тестов, которые подробно изложены в книге [8]. Весьма существенно, что только один из 29 тестов предполагает знакомство испытуемых с химией.

Предложенная система оказалась чрезвычайно полезной для ранней профориентации школьников. По этой системе ещё в 1980-е годы было протестировано около тысячи старшеклассников, многие из которых выбрали профессию химика. В настоящее время разработанный комплект тестов успешно используется в ряде регионов России и Белоруссии педагогами и школьниками для профконсультаций.

Выводы. Раннее формирование мотивации к изучению химии у младших школьников исключительно важно для фрормирования в будущем прочных и осознанных химических знаний и умений.

Существует комплексная система тестирования химических способностей у школьников, которая оказалась полезной как для предсказания их будущих достижений, так и для ранней профориентации.

Грамотно построенный химический эксперимент является хорошим средством повышения мотивации учения. Необходимо обучение учителей приёмам оптимизации химического эксперимента в направлении усиления его инорормационности, оперативности и экономичности.

\section{БЫБЛИОГРАФИЧЕСКИЙ СПИСОК:}

1. Жилин Д.М. Химический эксперимент в российских школах. Российский химический журнал. 2011, № 4, C. 48-56. URL: http://www.chem.msu.su/ rus/jvho/2011-4/48.pdf.

2. Мишурина О.А., Муллина Э.Р. Эксперимент как средство повышения мотивации учения в системе профессиональной подготовки студентов. URL: https://applied-research.ru/ru/article/view?id=10984.

3. Денисова Т.А. (н.Д.). Использование демонстрационного эксперимента на уроках химии при формировании познавательного интереса. URL: https:// multiurok.ru/files/ispolzovanie-demonstratsionnogoeksperimenta-na-ur.html.

4. Зенкович А.А. Роль химического эксперимента в развитии мотивации учащихся. Caŭm videouroki.net. 15 окT. 2017 г. URL: https://videouroki.net/razrabotki/ rol-khimichieskogho-ekspierimienta-v-razvitii-motivatsiiuchashchikhsia.html. 
5. Форум химиков-энтузиастов. Химия и химики. URL: http://chemistry-chemists.com/forum/viewforum. php?f=6\&sid=d767f4d3990132ed5a03f6c927581dad.

6. Royal Society of Chemistry. Education. Inspiring your teaching and Learning. Practical Resources. URL: http://www.rsc.org/learn-chemistry/collections/ experimentation.
7. Лисичкин Г.В. Химические способности возможность их диагностики. URL: http://www.chem.msu.ru/rus/books/2012/ science-education-2012/157.pdf.

8. Лисичкин Г.В., Коробейникова Л.А. Годитесь ли вы в химики? Москва : ИКЦ «Академкнига», 2003, 144 C. 